This item was submitted to Loughborough's Research Repository by the author.

Items in Figshare are protected by copyright, with all rights reserved, unless otherwise indicated.

\title{
An acute bout of swimming increases post-exercise energy intake in young healthy men and women
}

PLEASE CITE THE PUBLISHED VERSION

https://doi.org/10.1016/j.appet.2020.104785

PUBLISHER

Elsevier

VERSION

AM (Accepted Manuscript)

PUBLISHER STATEMENT

This paper was accepted for publication in the journal Appetite and the definitive published version is available at https://doi.org/10.1016/j.appet.2020.104785.

\section{LICENCE}

CC BY-NC-ND 4.0

\section{REPOSITORY RECORD}

Thackray, Alice, Scott Willis, Aron Sherry, David Clayton, David Broom, Mayada Demashkieh, Jack Sargeant, et al.. 2020. "An Acute Bout of Swimming Increases Post-exercise Energy Intake in Young Healthy Men and Women”. Loughborough University. https://hdl.handle.net/2134/12482012.v1. 


\section{An acute bout of swimming increases post-exercise energy intake in young healthy men}

and women

3 Alice E. Thackray ${ }^{\mathrm{a}, \mathrm{b}}$, Scott A. Willis ${ }^{\mathrm{a}, \mathrm{b}}$, Aron P. Sherry ${ }^{\mathrm{a}, \mathrm{b}}$, David J. Clayton ${ }^{\mathrm{c}}$, David R. Broom

4 d, Mayada Demashkieh ${ }^{\mathrm{e}}$, Jack A. Sargeant ${ }^{\text {b,f }}$, Lewis J. James ${ }^{\text {a }}$, Graham Finlayson ${ }^{\mathrm{g}}$, David J.

5 Stensel $^{\text {a,b }}$, James A. King a,b

$7 \quad{ }^{a}$ National Centre for Sport and Exercise Medicine, School of Sport, Exercise and Health

8 Sciences, Loughborough University, UK; A.E.Thackray@lboro.ac.uk (AET),

9 S.Willis2@1boro.ac.uk (SAW), A.P.Sherry@1boro.ac.uk (APS), L.James@1boro.ac.uk (LJJ),

10 D.J.Stensel@1boro.ac.uk (DJS), J.A.King@lboro.ac.uk (JAK).

$11{ }^{\mathrm{b}}$ National Institute for Health Research (NIHR) Leicester Biomedical Research Centre,

12 University Hospitals of Leicester NHS Trust and University of Leicester, Leicester, UK;

13 js928@1eicester.ac.uk (JAS).

$14{ }^{\mathrm{c}}$ School of Science and Technology, Nottingham Trent University, UK;

15 David.Clayton@ntu.ac.uk (DJC).

$16{ }^{\mathrm{d}}$ Academy of Sport and Physical Activity, Sheffield Hallam University, UK;

17 D.R.Broom@shu.ac.uk (DRB).

$18{ }^{\mathrm{e}}$ Department of Physical Education and Sport Science, Nanyang Technological University,

19 Singapore; Mayada.Demashkieh@,nie.edu.sg (MD).

$20{ }^{\mathrm{f}}$ Diabetes Research Centre, University of Leicester, UK

21 g Faculty of Medicine and Health, University of Leeds, UK; G.S.Finlayson@leeds.ac.uk 22 (GSF).

24 Address for correspondence

25 Dr James King

26 Senior Lecturer in Exercise Physiology

27 School of Sport, Exercise and Health Sciences

28 Loughborough University

29 Leicestershire

30 United Kingdom

31 LE11 3TU

32 Phone: +44(0)1509 228457 
33 Email: j.a.king@,lboro.ac.uk

34 Declarations of interest: None.

35 Abbreviations: CI, confidence intervals; ES, effect size; LFPQ, Leeds Food Preference

36 Questionnaire; METs, metabolic equivalents; PFC, prospective food consumption; RPE, rating

37 of perceived exertion

38 Key words: exercise, appetite, energy homeostasis, food intake, food reward 


\section{Introduction}

40

The interaction between exercise and appetite control is an important issue which holds relevance for energy balance and weight management (Blundell, Gibbons, Caudwell, Finlayson, \& Hopkins, 2015; Stensel, 2011). Over the last twenty years, many research groups have scrutinised how exercise, of various forms, impacts on appetite perceptions, ad libitum energy intake and appetite-related hormones (Dorling et al., 2018). The consensus of this research is that single bouts of moderate- to high-intensity exercise transiently suppress appetite, but do not influence subsequent ad libitum energy intake on the day exercise is performed (Deighton \& Stensel, 2014; Schubert, Desbrow, Sabapathy, \& Leveritt, 2013). This knowledge supports a therapeutic role of exercise in weight control given its ability to induce an energy deficit without eliciting compensation, at least in the short term.

An understanding of the relationship between exercise and appetite control has been derived from studies employing predominantly land-based forms of exercise, most notably running and cycling. This fact is relevant because anecdotal (Burke, 2007), and preliminary experimental data (King, Wasse, \& Stensel, 2011), suggests that swimming may stimulate appetite and energy intake. This contention is supported by the findings from two studies showing that water-based exercise (submerged cycling) stimulated post-exercise energy intake (Dressendorfer, 1993; White, Dressendorfer, Holland, McCoy, \& Ferguson, 2005). Direct investigations of appetite and energy intake responses to acute swimming have demonstrated that swimming had no effect on post-exercise energy intake (King, Wasse, \& Stensel, 2011; Lambert, Flynn, Braun, Boardley, 1999), but evoked a weaker satiety response to a postexercise meal (King, Wasse, \& Stensel, 2011). Unfortunately, these studies are limited by the inclusion of small, male only samples; and the lack of a true control trial (resting) along with a 
matched land-based exercise trial. The latter represents an essential study design feature, to isolate the effects of swimming from exercise per se.

In recent years, the interaction between exercise and the hedonic value of food has received increasing attention from the scientific community (Berthoud, 2011; Finlayson \& Dalton, 2012). That is, researchers have been interested to determine whether exercise may alter the perceived or expected pleasure-giving value of food along with the motivation to consume certain foods. These factors have been conceptualised as 'liking and wanting' and can be assessed using the Leeds Food Preference Questionnaire (LFPQ) (Dalton \& Finlayson, 2014). Research examining the acute effects of exercise on liking and wanting of foods has thus far produced mixed findings. Specifically, some studies have indicated that aerobic and resistance exercise decrease the relative preference for high-fat vs. low-fat foods (McNeil, Cadieux, Finlayson, Blundell, \& Doucet, 2015), whereas other studies suggest no impact of various forms of exercise on reward-related parameters (Alkahtani, Aldayel, \& Hopkins, 2019; Martins et al., 2015; Thivel et al., 2020). Given previous evidence hinting that water-based exercise may stimulate a drive to eat, it is possible that swimming may influence appetite-related reward parameters, but further work is required to investigate this hypothesis empirically.

The primary aim of this study was to directly compare the acute effects of exertion-matched swimming and cycling on appetite, energy intake, and food preference and reward in men and women. As a secondary exploratory aim, we sought to determine the modulating effect of sex on key study outcomes. Based on existing evidence, our primary hypothesis was that swimming, but not cycling, would increase appetite, ad libitum energy intake and the motivation and preference to consume high-fat and sweet foods. 


\subsection{Ethical approval and participants}

88

89

90

91

This study received approval from Loughborough University's Research Ethics Committee (R17-P059) before any trial-related procedures commenced. Seventeen healthy men and 15 healthy women (total $n=32$ ) were recruited from the local community and provided written informed consent to participate. To avoid awareness of the research aims affecting key study outcomes, information sheets provided to participants stated that the study sought to examine the impact of exercise on mood, stress and arousal. Participants were debriefed about the true aims of the study after the final experimental trial. Participants were: young adults (aged $<40$ years), without obesity (body mass index $<30 \mathrm{~kg} / \mathrm{m}^{2}$ ) and did not smoke or possess diagnosed metabolic health conditions. Participants were habitually active and able to swim and cycle at a recreational level (not elite). Participants reported being weight stable $(<2 \mathrm{~kg}$ body mass change) in the three months before the study. All female participants reported being eumenorrheic and not pregnant. Table 1 provides details of the participants who completed the study.

\subsection{Pre-assessment and familiarisation}

Participants attended the laboratory on one occasion before the main trials to permit the collection of baseline data and to be familiarised with important study procedures. Measurements of stature and body mass were made using an integrated stadiometer and scale (285, Seca GmbH \& Co.KG, Germany), whilst body fat percentage was estimated using bioelectrical impedance analysis (BC-418, Tanita, UK). Participants subsequently completed the Three Factor Eating Questionnaire (Stunkard AJ \& Messick S, 1985) and were familiarised with the $100 \mathrm{~mm}$ visual analogue (appetite) scales (Flint, Raben, Blundell, \& Astrup, 2000), the LFPQ (Dalton \& Finlayson, 2014), rating of perceived exertion scale (Borg, 1973), exercise 
110 procedures and the ad libitum test meal. Notably, participants were familiarised with the entire

111 ad libitum test meal procedure. Acceptability of the meal was subsequently confirmed by

112 ensuring that a 'reasonable' amount of food had been consumed, and secondly, through

113 participant dialogue.

\section{2.3. Study design and procedures}

115 Participants completed three main experimental trials (swimming, cycling, control) in a

116 crossover fashion, with the order of trials being randomised. Because a single bout of exercise

117 can affect energy intake for up to three days later (Rocha, Paxman, Dalton, Winter, \& Broom,

118 2013), an interval of at least four days separated each main experimental trial. For women, all

119 trials occurred during the follicular phase (days $1-7$ ) of the menstrual cycle. Figure 1 provides

120 a schematic overview of the study design.

121 On the morning of each main trial, participants consumed a breakfast meal at 08:45 in their

122 own home. This meal was prepared by the research team and provided to participants in

123 advance. Compliance with the timing of this meal was confirmed by the research team.

124 Participants subsequently arrived at the research centre at 10:00 where they remained until the

125 end of the experimental trial. In the control trial, participants rested in the laboratory for the

126 trial duration. Between 10:30 (0 h) and 11:30 (1 h), five-min expired gas samples were

127 collected into Douglas bags every $15 \mathrm{~min}$ to permit the calculation of resting energy

128 expenditure and substrate oxidation via indirect calorimetry (Frayn, 1983). At 11:45 (1.25 h),

129 participants sat in a room in isolation where they completed the LFPQ on a laptop. At 12:00

$130(1.5 \mathrm{~h})$, participants were provided with access to a homogeneous pasta meal which they were

131 free to consume ad libitum until 12:30 (2 h). Participants subsequently rested in the laboratory

132 for one additional hour (until 13:30). The purpose of this final hour, which included no

133 additional study procedures, was to reduce the likelihood that participants would not eat to 
134 'comfortable satiety' at the ad libitum meal, because of the impending opportunity to consume more desirable foods, or to engage in social eating opportunities, once outside of the laboratory.

136 Identical procedures were undertaken in the swimming and cycling trials except that 60 min 137 exercise protocols were undertaken between 10:30 (0 h) and 11:30 (1 h). Swimming was 138 undertaken at the institution's swimming pool $(25 \mathrm{~m})$ adjacent to the research laboratory, whilst 139 cycling was completed on a stationary ergometer (Lode Excalibur, Lode B.V., The Netherlands)

140 in the same laboratory where participants rested. In both exercise trials, the exercise protocols 141 consisted of six, eight min intervals of exercise separated by two min of rest. The interval nature

142 of the protocol was chosen to more closely resemble the intermittent pattern of leisure activity

143 which is often performed by recreational swimmers. To match the moderate- to high-intensity 144 exercise stimulus between swimming and cycling, participants were asked to work at a self145 reported target rating of perceived exertion (RPE) (Borg, 1973) of 15 ('hard') during the 146 exercise intervals. Heart rate was measured continuously by short-range telemetry (T31 Polar 147 Electro Ltd, Warwick, UK) as an objective assessment of exercise intensity. In the swimming 148 trial, participants were free to choose their stroke for each interval and rested between intervals 149 whilst stood in the pool at the end of the lane. The average speed of swimming was assessed 150 by monitoring the distance accumulated in each interval. In the cycling trial, participants self151 selected their power output in the first 20 seconds of each interval and then continued at that 152 exercise intensity for the remainder of the interval. Participants rested between intervals whilst 153 sat stationary on the cycle ergometer. The average power output for each interval was recorded 154 by the research team.

\subsection{Physical activity and dietary standardisation}

156 Participants recorded all food and drink consumed in the $24 \mathrm{~h}$ preceding the first experimental 157 trial, which was replicated in the $24 \mathrm{~h}$ before subsequent trials. Participants were required to 
consume their habitual diet during this period to ensure adequacy of endogenous carbohydrate stores. Alcohol, caffeine and structured physical activity were not permitted within this same $24 \mathrm{~h}$ standardisation period. Participants arrived at the laboratory via the same mode of

161 transport for each main trial having fasted from 22:00 the previous evening. Participants living 162 within one mile walked slowly to the laboratory, whilst those living further away arrived via 163 motorised transport.

\subsection{Appetite and environmental conditions}

165 Subjective perceptions of hunger, fullness, satisfaction and prospective food consumption

166 (PFC) were measured using $100 \mathrm{~mm}$ appetite scales at five strategically determined time-points

167 during main trials $(0 \mathrm{~h}$ [pre-exercise/rest], $1 \mathrm{~h}$ [post-exercise/rest], $1.25 \mathrm{~h}$ [pre-LFPQ], $1.5 \mathrm{~h}$

168 [pre ad libitum meal], $2 \mathrm{~h}$ [post ad libitum meal]). These questions were interspersed with 100

$169 \mathrm{~mm}$ scales relating to mood, stress and arousal as part of the blinding process within the study.

170 Environmental temperature and humidity were measured during exercise or rest $(0-1 \mathrm{~h})$ using 171 a handheld hygrometer (Omega RH85, UK). The temperature of the swimming pool was 172 measured using a glass thermometer (Fisher Scientific, UK).

\subsection{Study meals}

174 The standardised breakfast provided to study participants consisted of a strawberry jam sandwich, croissant and orange juice (69\% carbohydrate, $22 \%$ fat and $9 \%$ protein). This

176 contained $2720 \mathrm{~kJ}$ for men and $2200 \mathrm{~kJ}$ for women, which based on our previous research, 177 provided $25 \%$ of daily (sex-specific) energy requirements (Alajmi et al., 2016; King, Wasse, 178 Ewens, et al., 2011). Ad libitum energy intake was assessed from a homogeneous meal 179 containing pasta, tomato sauce and olive oil ( $72 \%$ carbohydrate, $12 \%$ protein, $16 \%$ fat, $6.5 \mathrm{~kJ}$

180 per gram). These ingredients were combined in advance of trials and the meal was reheated 181 before serving to participants. Consumption of individual macronutrients was determined by 
182 calculating the amount of energy consumed from each macronutrient and then dividing that

183 value by the energy equivalent for carbohydrate $(17 \mathrm{~kJ} / \mathrm{g})$, fat $(37 \mathrm{~kJ} / \mathrm{g})$ and protein $(17 \mathrm{~kJ} / \mathrm{g})$.

184 Participants were provided with access to the meal for $30 \mathrm{~min}$ and were instructed to eat until

185 'comfortably full and satisfied'. Participants ate the meal in a room with no external influences

186 and were required to self-serve from a large bowl containing an amount of pasta in excess of

187 expected consumption ( $\sim 1 \mathrm{~kg}$ cooked pasta). The mass of food consumed was determined by

188 subtracting the mass of food remaining (including leftovers) from that initially presented.

189 Absolute energy intake was deduced using nutritional information provided by the food

190 manufacturers. Relative energy intake was calculated for the swimming and cycling trials by

191 subtracting the net energy expenditure of exercise from the absolute energy intake during the

192 homogenous meal.

\subsection{Leeds Food Preference Questionnaire}

194 At 11:45 (1.25 h) in all trials, participants completed the LFPQ which is a validated laptop-

195 based procedure that measures food preference and reward (Finlayson, King, \& Blundell, 2008).

196 The LFPQ provides measures of wanting and liking for an array of food images which vary in

197 fat content and taste. The conduct and analysis of this questionnaire have been described in 198 depth previously (Dalton \& Finlayson, 2014). In brief, sixteen different food items, spanning

199 four categories (high-fat savoury, low-fat savoury, high-fat sweet, low-fat sweet) were 200 employed. To obtain the measurement of 'relative preference', participants were required to

201 select the food they 'most want to eat now' from paired combinations presented simultaneously.

202 Implicit wanting was ascertained by examining the reaction time for these choices, adjusted for 203 frequency of choice for each category. Explicit liking and explicit wanting were determined by 204 asking participants to rate the extent to which they 'liked' or 'wanted' each randomly presented 205 food item with a $100 \mathrm{~mm}$ visual analogue scale. Bias scores for fat appeal and sweet appeal 
were ascertained by subtracting the low-fat scores from the high-fat scores and then savoury

207 scores from the sweet scores, respectively.

\subsection{Exercise energy expenditure}

209 During the final minute of each cycling interval, a $60 \mathrm{~s}$ collection of expired gases was obtained

210 using Douglas bags to permit the assessment of energy expenditure using indirect calorimetry.

211 Specifically, the Haldane transformation was used to calculate inspired gas volumes and to

212 determine oxygen consumption $\left(\dot{\mathrm{V}}_{2}\right)$ and carbon dioxide production $\left(\dot{\mathrm{V}}_{2}\right)$ (Wilmore \&

213 Costill, 1973). Stoichiometric equations were then used to determine absolute quantities of fat

$214\left(1.67 \times \dot{\mathrm{VO}}_{2}-1.67 \times \dot{\mathrm{V} C O}_{2}\right)$ and carbohydrate $\left(4.55 \times \dot{\mathrm{V}}_{2}-3.21 \times \dot{\mathrm{VO}}_{2}\right)$ oxidised (assuming

215 negligible protein oxidation) (Frayn, 1983). Total energy expenditure was subsequently

216 determined by multiplying oxidised substrates by 39 and $17 \mathrm{~kJ} / \mathrm{gram}$, respectively.

217 For each swimming interval, participants were free to choose their stroke, however, the selected

218 stroke had to be maintained for the entire interval. The energy expenditure elicited during each

219 swimming interval was estimated using Metabolic Equivalents (METs) specific to the

220 swimming stroke and speed: recreational breaststroke (5.3 METs), recreational backstroke (4.8

221 METs), slow front crawl ( $\leq 0.95 \mathrm{~m} / \mathrm{s} ; 5.8 \mathrm{METs})$, fast front crawl $(>0.95 \mathrm{~m} / \mathrm{s} ; 9.8 \mathrm{METs})$

222 (Ainsworth et al., 2019). Total exercise-related energy expenditure during swimming was

223 derived by summing the energy expenditure for each exercise interval. The net energy

224 expenditure of each exercise mode was determined by subtracting each participants' resting

225 energy expenditure (during control) from the gross exercise-induced energy expenditure.

\section{2.9. Statistical analyses}

227 Data were analysed using the software package IBM SPSS Statistics for Windows version 24.0

228 (IBM Corporation, New York, USA). Appetite perceptions are presented and analysed relative 
to baseline $(0 \mathrm{~h})$ values (delta). Time-averaged total area under the curve for delta appetite 230 perceptions were calculated using the trapezoidal method. The model residuals for all outcome 231 variables were explored using histograms. All variables were deemed to show parity to a 232 Gaussian distribution and are presented as mean \pm SD.

233 Linear mixed models were used to examine between trial (swimming vs. cycling) differences 234 in exercise responses. Energy and macronutrient intakes, baseline $(0 \mathrm{~h})$ and delta area under 235 the curve for appetite perceptions, and food preference and reward scores were examined using 236 linear mixed models with trial (control, cycling, swimming) modelled as the sole fixed effect.

237 Differences in delta appetite perceptions over time were explored using linear mixed models 238 with trial (control, cycling, swimming) and time $(0,1,1.25,1.5$ and $2 \mathrm{~h})$ modelled as fixed 239 effects. An exploratory analysis was conducted for all outcomes with sex modelled as a fixed 240 effect and with a sex-by-trial interaction term. All models were adjusted for the period effect 241 to account for any change in responses over time irrespective of trial (Senn, 1993).

242 Absolute standardised effect sizes (ES) were calculated to supplement important findings and 243 thresholds of $0.2,0.5$, and 0.8 describe small, moderate, and large effects, respectively (Cohen, 244 1989). Mean differences and the respective $95 \%$ confidence intervals (95\% CI) are presented. 245 Exact $\mathrm{P}$ values (to 3 decimal places) are reported except for very small values which are 246 displayed as $\mathrm{P}<0.001$. Interpretation of the data is based on the $95 \% \mathrm{CI}$ and ES rather than 247 more conventional dichotomous hypothesis testing (Wasserstein et al., 2019). 


\section{Results}

254

\subsection{Exercise responses}

255 During the 48 min of swimming, the mean distance completed was $1,543 \pm 393 \mathrm{~m}$ at an average speed of $0.54 \pm 0.14 \mathrm{~m} / \mathrm{s}$. To complete the swimming sessions, some participants maintained a single stroke (front crawl $n=7$; breaststroke $n=11$; backstroke $n=1$ ) whereas others used a combination of front crawl, breaststroke and backstroke $(n=13)$. During cycling, a mean power output of $121 \pm 38$ watts was completed.

The 95\% CI for the mean difference in heart rate elicited during swimming and cycling overlapped zero $(146 \pm 15$ vs. $143 \pm 18$ beats $/ \mathrm{min}$, respectively; $\mathrm{ES}=0.20,95 \% \mathrm{CI}-1,8$ beats $/$ min, $\mathrm{P}=0.085)$. Mean RPE was marginally higher during swimming than cycling $(15.2$ \pm 0.7 vs. $14.9 \pm 0.6$, respectively; $\mathrm{ES}=0.52,95 \% \mathrm{CI} 0.1,0.6, \mathrm{P}=0.005)$, whereas estimated net energy expenditure was lower during swimming than cycling (1088 \pm 286 vs. $1684 \pm 580$ $\mathrm{kJ}$, respectively; $\mathrm{ES}=1.30,95 \% \mathrm{CI}-820,-387 \mathrm{~kJ}, \mathrm{P}<0.001)$.

\subsection{Energy intake}

267 A main effect of trial was identified for absolute $(\mathrm{P}=0.017)$ and relative $(\mathrm{P}<0.001)$ energy intake (Table 2). Swimming increased absolute energy intake compared to control $(\mathrm{ES}=0.47$, $\mathrm{P}=0.005)$, whereas the magnitude of increase was smaller after cycling compared to control

$270(\mathrm{ES}=0.31, \mathrm{P}=0.062)($ Figure $2 \mathrm{~A}$, Table 2). The difference in absolute energy intake between swimming and cycling was trivial $(\mathrm{ES}=0.16, \mathrm{P}=0.324)$ (Figure $2 \mathrm{~A}$, Table 2). Relative energy intake (absolute energy intake minus the net energy expenditure of exercise) was lower than control in the swimming $(\mathrm{ES}=0.39, \mathrm{P}=0.045)$ and cycling $(\mathrm{ES}=1.02, \mathrm{P}<0.001)$ trials. 
274 Relative energy intake was higher in the swimming trial than the cycling trial $(\mathrm{ES}=0.63, \mathrm{P}=$ 275 0.001) (Table 2).

\subsection{Ratings of perceived appetite}

277 Ratings of perceived hunger, fullness, satisfaction and PFC were similar across trials at baseline $278(0 \mathrm{~h})($ all $\mathrm{P} \geq 0.422)$ (Table 3$)$. A main effect of trial was identified for delta hunger $(\mathrm{P}<0.001)$, 279 fullness $(\mathrm{P}=0.039)$ and $\mathrm{PFC}(\mathrm{P}=0.001)$ but not satisfaction $(\mathrm{P}=0.309)$, but no trial-by-time 280 interactions were observed (all $\mathrm{P} \geq 0.352$ ) (Figure 3). Delta hunger and PFC were higher and 281 delta fullness was lower than control in the swimming (all $\mathrm{ES} \geq 0.20, \mathrm{P} \leq 0.017$ ) and cycling 282 (all $\mathrm{ES} \geq 0.16, \mathrm{P} \leq 0.051$ ) trials; the two exercise trials were similar (all $\mathrm{ES} \leq 0.15, \mathrm{P} \geq 0.082$ ).

283 The area under the curve for delta appetite perceptions were similar across trials (all $\mathrm{P} \geq 0.106)$ 284 (Table 3, Figure 3).

\subsection{Food preference and reward}

286 Fat and sweet appeal bias scores for relative preference, explicit wanting and explicit liking, 287 and sweet appeal bias scores for implicit wanting were similar across trials (all $\mathrm{P} \geq 0.080$ )

288 (Table 4). The main effect of trial for implicit wanting fat appeal bias was not statistically 289 significant $(\mathrm{P}=0.055)$, but values were lower in the cycling compared to the control $(\mathrm{ES}=$ $290 \quad 0.25, \mathrm{P}=0.035)$ and swimming $(\mathrm{ES}=0.24, \mathrm{P}=0.038)$ trials (Table 4). The difference in 291 implicit wanting fat appeal bias between the swimming and control trial was trivial $(\mathrm{ES}=0.00$, $292 \mathrm{P}=0.973)($ Table 4).

\subsection{Exploratory analyses}

294 Exploratory analysis revealed no main effect of sex for swimming distance (men 1,509 \pm 376 $\mathrm{m}$, women 1,582 $\pm 420 \mathrm{~m}$; ES $=0.18,95 \% \mathrm{CI}-361,214 \mathrm{~m}, \mathrm{P}=0.606)$ or average swim speed (men $0.52 \pm 0.13 \mathrm{~m} / \mathrm{s}$, women $0.55 \pm 0.15 \mathrm{~m} / \mathrm{s} ; \mathrm{ES}=0.19,95 \% \mathrm{CI}-0.13,0.07 \mathrm{~m} / \mathrm{s}, \mathrm{P}=0.597)$ 
297 Mean cycling power output was higher in men than women (men $139 \pm 40$ watts, women 100

$298 \pm 22$ watts; $\mathrm{ES}=1.19,95 \%$ CI 15, 63 watts, $\mathrm{P}=0.002)$. Estimated net energy expenditure was,

299 on average, $280 \mathrm{~kJ}$ higher in men than women irrespective of exercise mode (ES $=0.64,95 \%$

$300 \mathrm{CI} 49,511 \mathrm{~kJ}, \mathrm{P}=0.020)$, but a trial-by-sex interaction was not apparent $(\mathrm{P}=0.273)$ (data not

301 shown).

302 An exploratory analysis with sex modelled as a fixed effect and with a trial-by-sex interaction

303 term revealed higher absolute energy intake in men (Figure 2B) than women (Figure 2C) (mean

304 difference: $1042 \mathrm{~kJ}$; ES =0.68, 95\% CI -1, $2085 \mathrm{~kJ}, \mathrm{P}=0.050)$. Men exhibited higher perceived

305 appetite at baseline $(0 \mathrm{~h})$ than women for hunger (mean difference: $13 \mathrm{~mm}$; ES $=0.46,95 \% \mathrm{CI}$

$3061,25 \mathrm{~mm}, \mathrm{P}=0.040$ ) and PFC (mean difference: $14 \mathrm{~mm} ; \mathrm{ES}=0.57,95 \% \mathrm{CI} 1,27 \mathrm{~mm}, \mathrm{P}=$

307 0.033). Sweet appeal bias scores were higher in men than women for explicit liking (mean

308 difference: $19 \mathrm{~mm}$; $\mathrm{ES}=0.89,95 \% \mathrm{CI}$ 4, $35 \mathrm{~mm}, \mathrm{P}=0.018$ ), explicit wanting (mean difference:

$30920 \mathrm{~mm}$; $\mathrm{ES}=0.86,95 \% \mathrm{CI}$ 4, $37 \mathrm{~mm}, \mathrm{P}=0.019$ ), and implicit wanting (mean difference: 34

$310 \mathrm{AU} ; \mathrm{ES}=0.85,95 \%$ CI 5, $63 \mathrm{AU}, \mathrm{P}=0.023)$.

311 Modelling sex as a fixed effect revealed no other main effects of sex $(\mathrm{P} \geq 0.069)$ or any trial-

312 by-sex interactions $(\mathrm{P} \geq 0.092)$ and did not alter interpretation of the main effects of trial or

313 trial-by-time interactions outlined previously when sex was omitted from the models.

314

315

316

317

318 


\section{Discussion}

322 The consensus from previous research suggests that single bouts of exercise do not elicit compensatory increases in appetite and energy intake in the hours afterwards (Dorling et al., 2018; Schubert et al., 2013). The interaction between exercise, appetite and energy intake has been investigated predominantly using land-based forms of exercise, such as running and cycling. Given preliminary evidence suggesting that swimming may augment appetite and energy intake (Burke, 2007; King, Wasse, \& Stensel, 2011), this study specifically examined the impact of swimming on appetite, energy intake, and food preference and reward. Importantly, responses to swimming were directly compared with an exertion-matched cycling

330 bout so that the influence of swimming could be distinguished from the effects of exercise per

331 se. In contrast to previous literature, our results show that a single bout of swimming increased ad libitum energy intake at a meal consumed shortly after exercise. This effect was consistent between men and women and the absolute increase was higher than that observed in the cycling

334 trial compared to control. Furthermore, this outcome was unrelated to food preference or 335 reward, which were largely unresponsive to both exercise modalities.

336 Two previous studies demonstrated no effect of a single bout of swimming on ad libitum energy 337 intake at meals consumed shortly after exercise (King, Wasse, \& Stensel, 2011; Lambert, Flynn, 338 Braun, Boardley, 1999). This finding, which contrasts the results from the present study, likely 339 relates to procedural differences between studies. For instance, Lambert et al (1999) studied a 340 small group of highly trained triathletes who completed $45 \mathrm{~min}$ bouts of vigorous-intensity ( $72 \%$

341 of maximum oxygen uptake) swimming and running. Participants' habituation to swimming, 342 and energy turnover more broadly, may have masked the responses that we have seen in 
individuals swimming, but not at a competitive level. Another relevant disparity is the method

344 used to assess ad libitum energy intake. In both previous studies, energy intake was assessed

345 from buffet style meals. Conversely, in the present study we implemented a single item

346 homogeneous meal because it is now recognised that homogeneous test meals provide greater

347 sensitivity to detect between-trial differences given the smaller variance in outcome and

348 reduced predisposition to overconsumption (Horner, Byrne, \& King, 2014; King et al., 2017).

349 Relating to this latter point, it is notable that across the exercise and rest trials, energy intake

350 was considerably greater (26-58\%) in the previous studies (King, Wasse, \& Stensel, 2011;

351 Lambert, Flynn, Braun, Boardley, 1999) compared with the present investigation. This may

352 have blunted the ability to test for differences between conditions in the previous experiments.

353 Anecdotally, it has been suggested that swimming increases appetite (Burke, 2007); and in our

354 previous experimental study, swimming elicited a weaker satiety response, verses a resting

355 control trial, at a meal consumed one hour post-exercise (King, Wasse, \& Stensel, 2011). In

356 the present study, participants reported being hungrier and less full throughout the swimming

357 trial in comparison to control. A similar response was witnessed in the cycling trial, although

358 visually this difference was apparent earlier in the swimming trial i.e. by the end of exercise.

359 The augmented appetite in response to swimming was consistent with our hypothesis; however,

360 we did not expect cycling to elicit a similar response. High-intensity exercise is typically

361 associated with appetite suppression and, therefore, the moderate- to high-intensity of exercise

362 undertaken in this study is likely to have had a permissive effect on appetite perceptions.

363 Interestingly, PFC was marginally higher in response to swimming vs. cycling. This finding is

364 consistent with the proportionally greater increase in energy intake after swimming (vs. control)

365 than cycling.

366 In a meta-analysis of 51 acute studies, it was concluded that exercise has a trivial effect on 367 energy intake consumed at meals within two hours after exercise cessation (Schubert et al., 
2013). This data highlights the uniqueness of our findings when comparing the results to previous evidence. In seeking to explain our novel outcome, it is relevant to note that energy expenditure is unlikely to be explanative. This is because energy expenditure was estimated to be higher on the cycling verses swimming trial. Instead, water immersion and associated changes in body temperature, are perhaps the most likely explanation for the stimulatory effect of swimming on post-exercise energy intake. This suggestion is supported by data showing that energy intake was increased after treadmill-based exercise undertaken in cool $\left(8-10^{\circ} \mathrm{C}\right)$ vs. neutral ambient temperatures (Crabtree \& Blannin, 2015; Wasse, King, Stensel, \& Sunderland, 2013); and after cycling submerged in cold $\left(20-22^{\circ} \mathrm{C}\right)$ vs. thermoneutral water (Dressendorfer, 1993; White et al., 2005). In the present study, the water temperature was $28 \pm 1^{\circ} \mathrm{C}$ which is lower than thermoneutral for humans $\left(34-35^{\circ} \mathrm{C}\right)$ (Craig \& Dvorak, 1966). Consequently, although swimming would have generated metabolic heat, it is likely that participants' prolonged contact with cool water would lead to net body heat loss. This has been theorised to be an important driver of food intake in homeotherms (Brobeck, 1948).

The precise mechanisms by which heat loss and/or cool water exposure augment energy intake are not clear and were beyond the scope of the present study. We have previously shown that swimming did not influence circulating levels of the hunger stimulating gut hormone, acylated ghrelin (King, Wasse, \& Stensel, 2011). However, others have shown that cold exposure reduces circulating leptin and its signalling within central appetite circuits (Reynés et al., 2017; Zeyl, Stocks, Taylor, \& Jenkins, 2004). This response could theoretically prompt an increase in energy intake and provides an interesting hypothesis for future experiments.

Given the importance of non-homeostatic influences governing appetite and food intake, a key purpose of this study was to explore the potential impact of swimming on food preference and reward. Using functional magnetic resonance imaging, running and cycling have previously

392 been shown to suppress hedonic responses to food cues in key reward-related brain regions 
393 (Crabtree, Chambers, Hardwick, \& Blannin, 2014; Evero, Hackett, Clark, Phelan, \& Hagobian,

394 2012). Furthermore, when employing the LFPQ, others have shown that aerobic and resistance

395 exercise reduce the explicit liking and relative preference for high fat vs. low fat foods (McNeil

396 et al., 2015). In contrast to our original hypothesis, food preference and reward were largely

397 unresponsive to both swimming and cycling. A tendency for cycling to reduce implicit wanting

398 fat appeal bias scores compared with swimming and control was the only documented finding

399 in our analyses. Taken collectively, these findings support the conclusions of others who have

400 suggested that the pattern of food reward is stable in the context of acute exercise (Martins et

401 al., 2015). In the present study it should be recognised that our sample size was not powered

402 specifically to assess the effect of exercise on food preference and reward. However, it is

403 notable that our sample size was twice that utilised by McNeil et al. (2015) who had sufficient

404 power to detect differences in exercise related LFPQ outcomes. Speculatively, given the

405 similarity in participants examined and trial procedures, it is possible that the higher intensity

406 of the exercise protocols employed by McNeil et al. (2015) explains the discrepant outcome

407 i.e. food preference and reward may be affected more by higher-intensity exercise. Nonetheless,

408 given the large variability in responses observed, our data indicates that recreational bouts of

409 moderate- to high-intensity exercise, with and without water immersion, have no consistent

410 impact on food preference or reward (assessed via the LFPQ).

411 Given the potential for sex-based differences in appetite control and energy homeostasis

412 (Hagobian \& Braun, 2010), we investigated the moderating effect of sex on study outcomes.

413 Overall, our analyses showed that sex did not modulate the key outcomes of this study.

414 Consequently, we can be confident that the key messages from our research can be generalised

415 to both men and women. This sensitivity analysis revealed that men tended to consume more

416 energy than women; however, this was consistent across trials. One interesting finding to

417 emerge from the LFPQ data was that men demonstrated a greater implicit wanting, and explicit 
wanting and liking, for sweet vs. savoury foods, in comparison to women. Again, however,

419 this was consistent across trials and additional studies are needed to determine the consistency 420 of this finding.

421 The present study has some notable strengths and limitations which should be recognised. A key strength of our study was that it included a large sample that was almost equally composed of men and women. This has enabled us to explore the potential for sex-based interactions within our data. The importance of this is underscored by the recognition that women have traditionally been underrepresented in many aspects of health-based research (Feldman et al., 2019); particularly relating to energy balance where menstrual standardisation is necessary. Limitations include the short duration of the observation period which restricts the ability to discern whether the impact of swimming on energy intake is enduring and likely to influence energy balance meaningfully over the long-term. In a holistic sense, the stimulatory effect of swimming on energy intake was relatively small $(\sim 598 \mathrm{~kJ})$ and it is unclear whether this difference would be augmented or negated at subsequent post-exercise meals. Additionally, for practical reasons, our study did not include a non-exercise, water immersion trial, and therefore it is not possible to determine whether the influence of swimming on energy intake was due to an interaction between exercise and water immersion, or water immersion per se. Finally, it should be noted that energy expenditure in the swimming trial was estimated using METs

436 whereas direct measurements (indirect calorimetry) were undertaken in the cycling trial.

437 Relative energy intake data, specifically within the swimming trial, should therefore be viewed 438 with caution. Future studies should strive to obtain more precise measures of energy 439 expenditure during swimming which can be directly measured using modified indirect 440 calorimetry apparatus (Rodríguez, Keskinen, Kusch, \& Hoffmann, 2008).

441 In conclusion, a single bout of moderate- to high-intensity swimming increased ad libitum 442 energy intake in a sample of recreationally active men and women. The magnitude of increase 
443 after swimming (vs control) was greater than that observed after an exertion-matched cycling

444 trial (vs control), which contributed to a greater relative energy intake after swimming. This

445 response does not appear to be related to differences in food preference or reward. Additional

446 studies are needed to characterise the longer-term influence of swimming on appetite and

447 energy intake and to define the acute orexigenic mechanism(s).

\section{Acknowledgements}

449 We would like to thank the following individuals for their assistance with data collection: Zack

450 Ioannides, Victoria Gunn, Rebecca Link, Charlotte Fisher, Sharmada Venkat, Jacob Browne,

451 Sosie Cox, Kerstin Pum, Michelle Hogan, Daniel Murphy, Phillipa Fleming.

\section{Author contributions}

453 JAK, DJS, AET, LJJ, DRB and, DJC conceived the study idea. JAK, GSF, SW, JAS, MD and 454 AS performed data collection. AET and JAK conducted the data analysis and led the writing 455 of the manuscript. All authors reviewed and approved the final version of the manuscript.

\section{Funding}

457 The research was funded by the National Institute for Health Research (NIHR) Leicester

458 Biomedical Research Centre. The views expressed are those of the authors and not necessarily 459 those of the NHS, the NIHR or the Department of Health and Social Care. 


\section{References}

461 Ainsworth, B., Haskell, W., Herrmann, S., Meckes, N., Bassett, J. D., Tudor-Locke, C., ... 462 Leon, A. (2019). The Compendium of Physical Activities Tracking Guide. Retrieved June 19, 2019, from https://sites.google.com/site/compendiumofphysicalactivities/home

464

465

466

467

468

469

470

471

472

473

474

475

476

477

478

479

480

481

Alajmi, N., Deighton, K., King, J. A., Reischak-Oliveira, A., Wasse, L. K., Jones, J., ... Stensel, D. J. (2016). Appetite and Energy Intake Responses to Acute Energy Deficits in Females versus Males. Medicine and Science in Sports and Exercise, 48(3), 412-420. https://doi.org/10.1249/MSS.0000000000000793

Alkahtani, S., Aldayel, A., \& Hopkins, M. (2019). Effects of Acute Eccentric Exercise on Appetite-Related Hormones and Food Preferences in Men. American Journal of Men's Health, 13(4), 1-9. https://doi.org/10.1177/1557988319861587

Berthoud, H. R. (2011). Metabolic and hedonic drives in the neural control of appetite: Who is the boss? Current Opinion in Neurobiology, 21(6), 888-896. https://doi.org/10.1016/j.conb.2011.09.004

Blundell, J. E., Gibbons, C., Caudwell, P., Finlayson, G., \& Hopkins, M. (2015). Appetite control and energy balance: Impact of exercise. Obesity Reviews, 16(S1), 67-76. https://doi.org/10.1111/obr.12257

Borg, G. (1973). Percieved exertion: a note on history and methods. Medicine and Science in Sports, 5(2), 90-93.

Brobeck, J. R. (1948). Food intake as a mechanism of temperature regulation in rats. Federation Proceedings, 7(1), 13.

Burke, L. (2007). Practical Sports Nutrition. Champaign, IL: Human Kinetics. 
482

483

484

485

486

487

488

489

490

491

492

493

494

495

496

497

498

499

500

501

502

503

Cohen, J. (1989). Statistical power analysis for the behavioural sciences (2nd Editio). Hillsdale, NJ, USA: Lawrence Erlbaum Associates.

Crabtree, D. R., \& Blannin, A. K. (2015). Effects of exercise in the cold on ghrelin, PYY, and food intake in overweight adults. Medicine and Science in Sports and Exercise, 47(1), 49-57. https://doi.org/10.1249/MSS.0000000000000391

Crabtree, D. R., Chambers, E. S., Hardwick, R. M., \& Blannin, A. K. (2014). The effects of high-intensity exercise on neural responses to images of food. American Journal of Clinical Nutrition, 99(2), 258-267. https://doi.org/10.3945/ajcn.113.071381

Craig, A. B., \& Dvorak, M. (1966). Thermal regulation during water. Journal of Applied Physiology, 21(8), 1577-1585.

Dalton, M., \& Finlayson, G. (2014). Psychobiological examination of liking and wanting for fat and sweet taste in trait binge eating females. Physiology and Behavior, 136, $128-$ 134. https://doi.org/10.1016/j.physbeh.2014.03.019

Deighton, K., \& Stensel, D. J. (2014). Creating an acute energy deficit without stimulating compensatory increases in appetite: is there an optimal exercise protocol? Proceedings of the Nutrition Society, 73(2), 352-358. https://doi.org/10.1017/s002966511400007x

Dorling, J., Broom, D. R., Burns, S. F., Clayton, D. J., Deighton, K., James, L. J., ... Stensel, D. J. (2018). Acute and chronic effects of exercise on appetite, energy intake, and appetite-related hormones: The modulating effect of adiposity, sex, and habitual physical activity. Nutrients, 10(9), E1140. https://doi.org/10.3390/nu10091140

Dressendorfer, R. (1993). Effect of internal body temperature on energy intake soon after aerobic exercise. Medicine and Science in Sports and Exercise, 25, S42. 
504 Evero, N., Hackett, L. C., Clark, R. D., Phelan, S., \& Hagobian, T. A. (2012). Aerobic exercise reduces neuronal responses in food reward brain regions. Journal of Applied Physiology, 112(9), 1612-1619. https://doi.org/10.1152/japplphysiol.01365.2011

Feldman, S., Ammar, W., Lo, K., Trepman, E., Van Zuylen, M., \& Etzioni, O. (2019). Quantifying sex bias in clinical studies at scale with automated data extraction. JAMA Network Open, 2(7), 1-14. https://doi.org/10.1001/jamanetworkopen.2019.6700

Finlayson, G., \& Dalton, M. (2012). Hedonics of food consumption: are food 'liking' and 'wanting' viable targets for appetite control in the obese? Current Obesity Reports, 1(1),

Finlayson, G., King, N., \& Blundell, J. (2008). The role of implicit wanting in relation to 42-49. https://doi.org/10.1007/s13679-011-0007-2

Flint, A., Raben, A., Blundell, J. E., \& Astrup, A. (2000). Reproducibility, power and validity of visual analogue scales in assessment of appetite sensations in single test meal studies. International Journal of Obesity and Related Metabolic Disorders : Journal of the International Association for the Study of Obesity, 24(1), 38-48. https://doi.org/DOI: https://doi.org/10.1097/JES.0b013e3181c5cd98 
Horner, K. M., Byrne, N. M., \& King, N. A. (2014). Reproducibility of subjective appetite ratings and ad libitum test meal energy intake in overweight and obese males. Appetite, 81, 116-122. https://doi.org/10.1016/j.appet.2014.06.025

King, J. A., Deighton, K., Broom, D. R., Wasse, L. K., Douglas, J. A., Burns, S. F., ... Stensel, D. J. (2017). Individual variation in hunger, energy intake, and ghrelin responses to acute exercise. Medicine and Science in Sports and Exercise, 49(6), 12191228. https://doi.org/10.1249/MSS.0000000000001220

King, J. A., Wasse, L. K., Ewens, J., Crystallis, K., Emmanuel, J., Batterham, R. L., \& Stensel, D. J. (2011). Differential acylated ghrelin, peptide YY3-36, appetite, and food intake responses to equivalent energy deficits created by exercise and food restriction. Journal of Clinical Endocrinology and Metabolism, 96(4), 1114-1121. https://doi.org/10.1210/jc.2010-2735

King, J. A., Wasse, L. K., \& Stensel, D. J. (2011). The acute effects of swimming on appetite, food intake, and plasma acylated ghrelin. Journal of Obesity, 2011, ID 351628. https://doi.org/10.1155/2011/351628

Lambert, C.P., Flynn, M.G., Braun, W.A., Boardley, D. J. (1999). The effects of swimming and running on energy intake during 2 hours of recovery. J Sports Med Phys Fitness, $39(4), 348-54$.

Martins, C., Stensvold, D., Finlayson, G., Holst, J., Wisloff, U., Kulseng, B., ... King, N. A. (2015). Effect of moderate- and high-intensity acute exercise on appetite in obese individuals. Medicine and Science in Sports and Exercise, 47(1), 40-48. https://doi.org/10.1249/MSS.0000000000000372

McNeil, J., Cadieux, S., Finlayson, G., Blundell, J. E., \& Doucet, É. (2015). The effects of a 

single bout of aerobic or resistance exercise on food reward. Appetite, 84, 264-270. https://doi.org/10.1016/j.appet.2014.10.018

552

553

554

555

556

557

558

559

560

561

562

563

564

565

566

567

568

569

570

571

Reynés, B., Hazebroek, M. K., García-Ruiz, E., Keijer, J., Oliver, P., \& Palou, A. (2017). Specific features of the hypothalamic leptin signaling response to cold exposure are reflected in peripheral blood mononuclear cells in rats and ferrets. Frontiers in Physiology, 8(AUG), 1-11. https://doi.org/10.3389/fphys.2017.00581

Rocha, J., Paxman, J., Dalton, C., Winter, E., \& Broom, D. (2013). Effects of an acute bout of aerobic exercise on immediate and subsequent three-day food intake and energy expenditure in active and inactive men. Appetite, 71, 369-378. https://doi.org/10.1016/j.appet.2013.09.009

Rodríguez, F. A., Keskinen, K. L., Kusch, M., \& Hoffmann, U. (2008). Validity of a swimming snorkel for metabolic testing. International Journal of Sports Medicine, 29(2), 120-128. https://doi.org/10.1055/s-2007-964973

Schubert, M. M., Desbrow, B., Sabapathy, S., \& Leveritt, M. (2013). Acute exercise and subsequent energy intake. A meta-analysis. Appetite, 63, 92-104. https://doi.org/10.1016/j.appet.2012.12.010

Senn, S. (1993). Cross-over trials in clinical research. Chichester, UK: Wiley.

Stensel, D. (2011). Exercise, appetite and appetite-regulating hormones: Implications for food intake and weight control. Annals of Nutrition and Metabolism, 57(S2), 36-42. https://doi.org/10.1159/000322702

Stunkard AJ; Messick S. (1985). The three-factor eating questionnaire to measure dietary restraint, disinhibition and hunger. Journal of Psychometric Research, 29(1), 71-83. 
572 Thivel, D., Fillon, A., Genin, P. M., Miguet, M., Khammassi, M., Pereira, B., ... Metz, L.

573

574

575

576

577

578

579

580

581

582

583

584

585

586

587

588

589

590

591

592 (2020). Satiety responsiveness but not food reward is modified in response to an acute bout of low versus high intensity exercise in healthy adults. Appetite, 145(1), 104500. https://doi.org/10.1016/j.appet.2019.104500

Wasse, L. K., King, J. A., Stensel, D. J., \& Sunderland, C. (2013). Effect of ambient temperature during acute aerobic exercise on short-term appetite, energy intake, and plasma acylated ghrelin in recreationally active males. Applied Physiology, Nutrition and Metabolism, 38(8), 905-909. https://doi.org/10.1139/apnm-2013-0008

Wasserstein, R. L., Schirm, A. L., Lazar, N. A., Wasserstein, R. L., Schirm, A. L., \& Lazar, N. A. (2019). Moving to a World Beyond “ $p<0.05$." 1305(S1), 0-19. https://doi.org/10.1080/00031305.2019.1583913

White, L. J., Dressendorfer, R. H., Holland, E., McCoy, S. C., \& Ferguson, M. A. (2005). Increased caloric intake soon after exercise in cold water. International Journal of Sport Nutrition and Exercise Metabolism, 15(1), 38-47. https://doi.org/10.1123/ijsnem.15.1.38

Wilmore, J., \& Costill, D. (1973). Adequacy of the Haldane transformation in the computation of exercise VO2 in man. Journal of Applied Physiology, 35(1), 85-89.

Zeyl, A., Stocks, J. M., Taylor, N. a S., \& Jenkins, A. B. (2004). Interactions between temperature and human leptin physiology in vivo and in vitro. European Journal of Applied Physiology, 92(4-5), 571-578. https://doi.org/10.1007/s00421-004-1084-7 


\section{Figure legends}

594 Figure 1. Schematic representation of the main trial protocol. Arrow indicates participants

595 arrival at the laboratory, chequered rectangle indicates standardised breakfast, white rectangles

596 indicate swimming, cycling or rest (control), grey rectangle indicates the Leeds Food

597 Preference Questionnaire, and black rectangle indicates ad libitum pasta meal.

598 Figure 2. Absolute ad libitum energy intake in the control ( $\mathbf{\square})$, cycling $(\bigcirc)$ and swimming $(\triangle)$

599 trials in (A) all participants combined $(n=32)$, (B) male participants only $(n=17)$ and (c)

600 female participants only $(n=15)$. Data points represent individual data values and the black

601 solid line indicates the mean \pm SD. Panel A: main effect of trial $\mathrm{P}=0.017$ (cycling vs. control

$602 \mathrm{P}=0.062$; swimming vs. control $\mathrm{P}=0.005$; swimming vs. cycling $\mathrm{P}=0.324)$. Panels $\mathrm{B}$ and $\mathrm{C}$ :

603 main effect of sex $\mathrm{P}=0.050$; trial-by-sex interaction $\mathrm{P}=0.967$.

604 Figure 3. Delta ratings of perceived (A) hunger, (B) fullness, (C) satisfaction and (D) 605 prospective food consumption (PFC) in the control $(\mathbf{\square})$, cycling $(\bigcirc)$ and swimming $(\triangle)$ trials 606 in 17 men and 15 women. Data points on left hand figures represent mean \pm SEM. White

607 rectangle indicates swimming, cycling or rest (control), grey rectangle indicates Leeds Food

608 Preference Questionnaire, and black rectangle indicates ad libitum pasta meal. Main effect of 609 trial: hunger $\mathrm{P}<0.001$, fullness $\mathrm{P}=0.039$, satisfaction $\mathrm{P}=0.309, \mathrm{PFC} \mathrm{P}=0.001$. Data points

610 on right hand panels represent individual data points for time-averaged total area under the 611 curve and the black solid line represents the mean \pm SD. Main effect of trial all $\mathrm{P} \geq 0.106$. 
612 Table 1. Participant characteristics.

\begin{tabular}{|c|c|c|c|c|}
\hline & $\begin{array}{c}\text { All } \\
(n=32)\end{array}$ & $\begin{array}{c}\text { Men } \\
(n=17)\end{array}$ & $\begin{array}{l}\text { Women } \\
(n=15)\end{array}$ & $\begin{array}{l}\text { Main effect of sex } \\
\text { Men vs. women } \\
\text { Mean difference } \\
(95 \% \mathrm{CI})^{1}\end{array}$ \\
\hline Age (years) & $23 \pm 2$ & $24 \pm 2$ & $22 \pm 3$ & $2(-0.1,3)$ \\
\hline Stature $(\mathrm{m})$ & $1.71 \pm 0.08$ & $1.76 \pm 0.08$ & $1.65 \pm 0.04$ & $0.11(0.07,0.15)^{2}$ \\
\hline Body mass $(\mathrm{kg})$ & $70.7 \pm 12.8$ & $77.9 \pm 12.6$ & $62.4 \pm 6.6$ & $15.5(8.1,22.9)^{2}$ \\
\hline Body mass index $\left(\mathrm{kg} / \mathrm{m}^{2}\right)$ & $24.0 \pm 2.6$ & $25.0 \pm 2.6$ & $22.8 \pm 2.3$ & $2.1(0.4,3.9)^{2}$ \\
\hline Body fat $(\%)$ & $19.9 \pm 7.3$ & $14.8 \pm 4.5$ & $25.8 \pm 5.1$ & $-11.0(-14.5,-7.5)^{2}$ \\
\hline Lean body mass (kg) & $56.7 \pm 12.3$ & $66.1 \pm 9.1$ & $46.1 \pm 3.3$ & $20.0(14.9,25.0)^{2}$ \\
\hline \multicolumn{5}{|c|}{ Three Factor Eating Questionnaire } \\
\hline Dietary restraint & $9 \pm 5$ & $8 \pm 5$ & $9 \pm 5$ & $-1(-4,2)$ \\
\hline Dietary disinhibition & $6 \pm 2$ & $6 \pm 3$ & $6 \pm 2$ & $0(-2,2)$ \\
\hline Hunger & $6 \pm 3$ & $6 \pm 3$ & $6 \pm 3$ & $0(-2,2)$ \\
\hline
\end{tabular}

613 Values are mean \pm SD. Data were analysed using linear mixed models with sex (men or 614 women) included as a fixed factor.

$615{ }^{1}$ Mean difference and 95\% confidence interval of the mean absolute difference between men 616 and women.

$617 \quad{ }^{2}$ Main effect of sex $\mathrm{P} \leq 0.018$. 
618 Table 2. Ad libitum energy and macronutrient intakes in the control, cycling and swimming trials.

\begin{tabular}{|c|c|c|c|c|c|c|}
\hline & \multirow[b]{2}{*}{ Control } & \multirow[b]{2}{*}{ Cycling } & \multirow[b]{2}{*}{ Swimming } & \multicolumn{3}{|c|}{ Mean difference $(95 \% \mathrm{CI})^{1}$} \\
\hline & & & & Cycling vs. control & $\begin{array}{c}\text { Swimming vs. } \\
\text { control }\end{array}$ & $\begin{array}{l}\text { Swimming vs. } \\
\text { cycling }\end{array}$ \\
\hline Absolute energy intake $(\mathrm{kJ})$ & $3259 \pm 1265$ & $3652 \pm 1619$ & $3857 \pm 1611$ & $392(-21,805)$ & $598(185,1010)^{3}$ & $205(-207,618)$ \\
\hline Relative energy intake $(\mathrm{kJ})$ & $3259 \pm 1265$ & $1967 \pm 1675$ & $2769 \pm 1610$ & $-1277(-1742,-812)^{2}$ & $-475(-940,-10)^{3}$ & $802(337,1267)^{4}$ \\
\hline Protein $(\mathrm{g})$ & $23 \pm 9$ & $26 \pm 12$ & $28 \pm 12$ & $3(-0.1,6)$ & $4(1,7)^{3}$ & $1(-1,4)$ \\
\hline Carbohydrate (g) & $140 \pm 54$ & $157 \pm 70$ & $166 \pm 69$ & $17(-1,35)$ & $26(8,43)^{3}$ & $9(-9,27)$ \\
\hline Fat $(\mathrm{g})$ & $14 \pm 5$ & $16 \pm 7$ & $16 \pm 7$ & $2(-0.1,3)$ & $3(1,4)^{3}$ & $1(-1,3)$ \\
\hline
\end{tabular}

619 Values are mean \pm SD for $n=32$. Data were analysed using linear mixed models with trial (control, cycling or swimming) included as a fixed

620 factor and with adjustment for the period effect. A main effect of trial was identified for absolute energy, relative energy and macronutrient

621 intakes $(\mathrm{P} \leq 0.017)$.

$622{ }^{1}$ Mean difference and $95 \%$ confidence interval of the mean absolute difference between the experimental trials adjusted for the period effect.

$623{ }^{2}$ Cycling vs. control $\mathrm{P}<0.001$.

$624{ }^{3}$ Swimming vs. control $\mathrm{P} \leq 0.045$.

$625{ }^{4}$ Swimming vs. cycling $\mathrm{P}=0.001$. 
Table 3. Baseline and time-averaged total area under the curve for appetite perceptions in the control, cycling and swimming trials.

\begin{tabular}{|c|c|c|c|c|c|c|}
\hline & \multirow[b]{2}{*}{ Control } & \multirow[b]{2}{*}{ Cycling } & \multirow[b]{2}{*}{ Swimming } & \multicolumn{3}{|c|}{ Mean difference $(95 \% \mathrm{CI})^{1}$} \\
\hline & & & & Cycling vs. control & $\begin{array}{l}\text { Swimming vs. } \\
\text { control }\end{array}$ & $\begin{array}{l}\text { Swimming vs. } \\
\text { cycling }\end{array}$ \\
\hline \multicolumn{7}{|l|}{ Baseline (0 h) } \\
\hline Hunger (mm) & $33 \pm 23$ & $29 \pm 20$ & $29 \pm 24$ & $-5(-13,3)$ & $-4(-12,4)$ & $0(-7,8)$ \\
\hline Fullness (mm) & $55 \pm 25$ & $60 \pm 17$ & $57 \pm 22$ & $5(-4,14)$ & $2(-7,11)$ & $-3(-12,6)$ \\
\hline Satisfaction (mm) & $57 \pm 19$ & $58 \pm 20$ & $60 \pm 18$ & $1(-6,8)$ & $3(-4,10)$ & $2(-5,9)$ \\
\hline $\mathrm{PFC}(\mathrm{mm})$ & $42 \pm 23$ & $40 \pm 22$ & $39 \pm 22$ & $-2(-10,6)$ & $-3(-11,5)$ & $-1(-9,7)$ \\
\hline \multicolumn{7}{|c|}{ Time-averaged total area under the curve } \\
\hline Delta hunger $(\mathrm{mm} \mathrm{h})$ & $9.2 \pm 10.1$ & $13.6 \pm 15.8$ & $16.7 \pm 15.5$ & $4.4(-2.5,11.4)$ & $7.5(0.5,14.4)$ & $3.0(-3.9,10.0)$ \\
\hline Delta fullness ( $\mathrm{mm} \mathrm{h})$ & $-5.3 \pm 15.4$ & $-8.2 \pm 16.0$ & $-10.0 \pm 17.2$ & $-2.9(-10.1,4.3)$ & $-4.7(-11.9,2.5)$ & $-1.8(-9.0,5.4)$ \\
\hline Delta satisfaction $(\mathrm{mm} \mathrm{h})$ & $-2.8 \pm 11.2$ & $-0.4 \pm 12.0$ & $-1.3 \pm 15.1$ & $2.4(-3.5,8.3)$ & $1.5(-4.4,7.4)$ & $-0.9(-6.8,5.0)$ \\
\hline Delta PFC (mm h) & $5.8 \pm 12.4$ & $8.8 \pm 17.0$ & $12.8 \pm 12.5$ & $3.0(-3.8,9.9)$ & $7.0(0.2,13.9)$ & $4.0(-2.9,10.9)$ \\
\hline
\end{tabular}


Table 4. Measures of relative preference, implicit wanting, explicit wanting and explicit liking assessed 15 minutes after 60 minutes of exercise

\begin{tabular}{|c|c|c|c|c|c|c|}
\hline & \multirow[b]{2}{*}{ Control } & \multirow[b]{2}{*}{ Cycling } & \multirow[b]{2}{*}{ Swimming } & \multicolumn{3}{|c|}{ Mean difference $(95 \% \mathrm{CI})^{1}$} \\
\hline & & & & Cycling vs. control & $\begin{array}{c}\text { Swimming vs. } \\
\text { control }\end{array}$ & $\begin{array}{l}\text { Swimming vs. } \\
\text { cycling }\end{array}$ \\
\hline \multicolumn{7}{|l|}{ Relative preference } \\
\hline Fat appeal bias (AU) & $-4.0 \pm 11.0$ & $-1.8 \pm 10.8$ & $-4.0 \pm 9.5$ & $2.2(-0.5,4.9)$ & $0.1(-2.6,2.7)$ & $-2.2(-4.8,0.5)$ \\
\hline Sweet appeal bias (AU) & $-0.3 \pm 16.0$ & $0.8 \pm 14.5$ & $0.3 \pm 15.4$ & $1.1(-2.5,4.7)$ & $0.6(-3.0,4.2)$ & $-0.5(-4.1,3.2)$ \\
\hline \multicolumn{7}{|l|}{ Implicit wanting } \\
\hline Fat appeal bias (AU) & $12.9 \pm 33.0$ & $4.7 \pm 37.6$ & $12.7 \pm 30.9$ & $-8.2(-15.8,-0.6)$ & $-0.1(-7.7,7.5)$ & $8.0(0.5,15.6)$ \\
\hline Sweet appeal bias (AU) & $-1.9 \pm 43.0$ & $3.8 \pm 39.4$ & $2.2 \pm 41.0$ & $5.7(-4.8,16.3)$ & $4.1(-6.5,14.7)$ & $-1.6(-12.2,8.9)$ \\
\hline \multicolumn{7}{|l|}{ Explicit wanting } \\
\hline Fat appeal bias (mm) & $2.7 \pm 10.9$ & $1.2 \pm 14.8$ & $6.2 \pm 12.8$ & $-1.5(-6.0,2.9)$ & $3.4(-1.0,7.9)$ & $5.0(0.5,9.4)$ \\
\hline Sweet appeal bias (mm) & $-1.0 \pm 27.8$ & $0.4 \pm 22.1$ & $-2.2 \pm 20.6$ & $1.4(-3.9,6.7)$ & $-1.1(-6.4,4.2)$ & $-2.6(-7.8,2.7)$ \\
\hline \multicolumn{7}{|l|}{ Explicit liking } \\
\hline Fat appeal bias (mm) & $2.7 \pm 9.8$ & $0.6 \pm 14.9$ & $4.4 \pm 12.7$ & $-2.1(-6.2,1.9)$ & $1.7(-2.4,5.8)$ & $3.8(-0.3,7.9)$ \\
\hline Sweet appeal bias (mm) & $-2.4 \pm 24.6$ & $2.0 \pm 21.9$ & $0.2 \pm 20.7$ & $4.3(-0.8,9.4)$ & $2.6(-2.6,7.7)$ & $-1.7(-6.9,3.4)$ \\
\hline
\end{tabular}

${ }^{1}$ Mean difference and $95 \%$ confidence interval of the mean absolute difference between the experimental trials adjusted for the period effect. 